Fecha de recepción: febrero 2019 Fecha de aceptación: julio 2019 Versión final: noviembre 2020

\section{Design de um Produto com Tecnologia Assistiva para Inclusão de Crianças com Paralisia Cerebral na Rede de Ensino no Brasil}

Elton Moura Nickel ${ }^{1}$, Júlia Machado Padaratz², Paola

Camila Dias de Moraes ${ }^{3}$, Nathália Buch Abreu de Souza ${ }^{4}$

e Mirella Gomes Nogueira ${ }^{5}$

\begin{abstract}
Resumo: Este artigo apresenta os resultados do desenvolvimento de um produto com Tecnologia Assistiva (TA) de baixo custo para auxiliar educandos com Paralisia Cerebral (PC) em uma rede municipal de ensino no Brasil, em questões relativas à sua mobilidade, comportamento motor e à realização de atividades diversas, dentro e fora da sala de aula. $\mathrm{O}$ projeto foi colaborativo e orientado com o uso de métodos e ferramentas tradicionalmente utilizadas na área do design. A execução e implementação da proposta visam proporcionar aos educandos uma situação adequada para sua autonomia, interação e consequente inclusão nas atividades relativas ao seu próprio desenvolvimento humano.
\end{abstract}

Palavras chave: Tecnologia Assistiva - Paralisia Cerebral - Projeto Colaborativo.

[Resumos em espanhol e inglês na página 98]

(1) Doutor em Engenharia de Produção pela Universidade Federal de Santa Catarina (UFSC) e Professor Permanente do Programa de Pós-Graduação em Design da Universidade do Estado de Santa Catarina (UDESC).

(2) Bacharel em Design pela Universidade do Estado de Santa Catarina (UDESC).

(3) Graduanda em Design pela Universidade do Estado de Santa Catarina (UDESC).

\title{
Introdução
}

$\mathrm{Na}$ atual sociedade, são claras as possibilidades de se estimular as capacidades de crianças com Paralisia Cerebral (PC), ao promover ações que simplifiquem seus esforços no desempenho de suas atividades escolares. Contudo, poucas iniciativas têm priorizado os aspectos ergonômicos mais básicos para uma verdadeira inclusão do aluno com PC na rede de ensino: as tecnologias que auxiliem na mobilidade e na adequação postural necessárias para a realização das diversas atividades na escola. Este estudo, fundamentado na área da Tecnologia Assistiva (TA) -que trata do desenvolvimento de produtos, serviços e recursos para auxiliar pessoas com deficiência ou outras incapacidades-, é resultado de um projeto colaborativo e um convênio de cooperação técnica existente entre a Universidade do Estado de Santa Catarina (UDESC) e a Fundação Catarinense de Educação Especial (FCEE). 
O objetivo desta proposta é apresentar os resultados do desenvolvimento de um produto com TA de baixo custo, com vista a auxiliar educandos com PC da rede regular de ensino, em questões relativas à sua mobilidade, comportamento motor (principalmente adequação postural, equilíbrio e habilidades motoras) e à realização de atividades diversas (alimentação, higiene, reabilitação, aprendizagem, descanso e recreação), dentro e fora da sala de aula. Por sua vez, tem-se também como objetivos que a tecnologia gerada promova a autonomia e interação social dos educandos, resultando em inclusão, que gera autoestima e qualidade de vida e, ainda, que facilite o trabalho dos educadores.

\section{Fundamentação teórica}

\section{Paralisia Cerebral e a rede de ensino brasileira}

Paralisia Cerebral (PC) é uma expressão abrangente para diversos distúrbios que afetam a capacidade infantil para se mover e manter a postura e o equilíbrio. Esses distúrbios são causados por uma lesão cerebral que ocorre antes ou durante os primeiros dias do nascimento. Essa lesão não prejudica os músculos nem os nervos que os conectam à medula espinal -apenas a capacidade do cérebro para controlar esses músculos. Dependendo de sua localização e gravidade, a lesão cerebral que causa os distúrbios de movimento de uma criança também pode causar outros problemas, que incluem deficiência mental, convulsões, distúrbios de linguagem, transtornos de aprendizagem e problemas de visão e audição (Geralis, 2007).

Segundo Washington et. al. (2002), indivíduos com Paralisia Cerebral, em sua maioria, têm dificuldade para a manutenção da dinâmica corporal, principalmente na postura sentada, na qual é desenvolvida a maioria das atividades escolares, portanto se faz necessário pensar em recursos que possibilitem um sentar adequado, que ofereça conforto e segurança. Em complemento a Washington et. al. (2002), Bersch \& Pelosi (2007) afirmam que o alinhamento e a estabilidade postural são questões fundamentais para a realização de qualquer atividade. Uma postura adequada vai trazer vários benefícios para aluno em sala de aula, dentre eles, facilidade para manter o contato visual, realizar atividades de manipulação com os membros superiores, menor gasto energético e maior atenção durante a realização de atividades escolares.

Além disso, Rocha \& Deliberato (2012a), com base em dados do governo brasileiro, em documentos que regem a Educação Infantil, apontam ser fundamental a organização do seu espaço, de forma que elimine as barreiras arquitetônicas, adapte os mobiliários, selecione materiais adequados, realize as adaptações nos brinquedos e jogos. Esses procedimentos são instrumentos fundamentais para a prática educativa inclusiva com qualquer criança pequena, e junto à crianças com deficiência física se tornam condições essenciais e prioritárias. Tendo isso em vista, o uso da Tecnologia Assistiva na educação especial é proposto através de serviços, recursos e estratégias que permitem ao aluno com deficiência a sua acessibilidade, favorece o seu processo de aprendizagem e o desenvolvimento de diferentes habilidades (Bersch \& Pelosi, 2007; Rocha \& Deliberato, 2012b). Todavia, as 
diversidades de habilidades observadas em crianças com Paralisia Cerebral podem acarretar dificuldades em seu desempenho funcional e comprometer suas ações sobre o meio. O conhecimento sobre a participação da criança com Paralisia Cerebral na escola permite ao profissional identificar a diversidade de habilidades e necessidades de cada sujeito, o que favorece a possível prescrição do recurso de Tecnologia Assistiva adequado (Bersch \& Pelosi, 2007; Rocha \& Deliberato, 2012b).

$\mathrm{Na}$ escola, a criança, com paralisia ou não, passa por um período importante de desempenho ocupacional, uma vez que o ambiente e as pessoas inseridas nele a reconhecem por sua capacidade de realizar tarefas. Tendo isso em vista, Alves \& Matsukura (2011) afirmam que na fase escolar, não só o contexto físico e social se alarga e diferencia, mas também as expectativas do meio social se tornam mais exigentes, a dependência é menos tolerada, as regras implícitas de convivência ficam mais complexas e o suporte está menos disponível. A exposição ao julgamento é mais evidente e instiga a criança a corresponder às expectativas da família, do professor e dos companheiros. Logo, com base em Rocha \& Deliberato (2012b), que complementam os argumentos de Bersch \& Pelosi, (2007), é possível perceber que existe uma preocupação crescente em inserir o aluno com deficiência nas atividades pedagógicas. E é nesse contexto que a Tecnologia Assistiva, através de recursos adaptados e profissionais da área, traz a possibilidade de um melhor desenvolvimento e aquisição de habilidades da criança com Paralisia Cerebral.

Também é importante ressaltar que, com base em Oliveira (2007), é impossível existir uma cadeira ou móvel que se adeque a todos os indivíduos, pois é necessário levar em consideração, não só as necessidades de cada um, mas como suas limitações e medidas antropométricas. O tipo de assento, a regulação de sua inclinação e de seu encosto e as características da mesa de apoio são aspectos que devem ser considerados para proporcionar uma postura adequada e um maior conforto ao indivíduo.

Para compreender melhor a situação dos alunos com necessidades especiais na rede de ensino brasileira, é possível observar como exemplo o estudo dos pesquisadores Beckung \& Hagberg, que aborda as limitações funcionais de 176 crianças com Paralisia Cerebral em relação à mobilidade, educação e relações sociais. Nele, as crianças foram identificadas com níveis de I a V (com grau de gravidade crescente). As de nível motor I e II segundo o GMFCS e o Sistema de Graduação da Função Bimanual Fina - BFMF, não apresentaram limitações ou apresentaram limitações leves para frequentar a escola comum. Já as crianças do nível motor III apresentaram restrições moderadas a severas, e as crianças do nível IV e V tiveram limitação severa ou completa nas relações sociais e necessitaram de suporte pessoal ou ajustes especiais para frequentarem a escola comum (Alves \& Matsukura, 2011).

Dessa forma, percebe-se que, assim como Rocha \& Deliberato (2012a) afirmam, existe de fato a necessidade de inserir diversos tipos de Tecnologia Assistiva nas redes de ensino para que haja uma melhor integração entre os educandos especiais, os educadores e os demais envolvidos no ambiente escolar. Com o intuito de estudar e entender as possibilidades dessa integração, no âmbito internacional, as pesquisas envolvendo o tema Tecnologia Assistiva têm permeado algumas linhas de investigação como: estudos sobre os modelos teóricos para a implementação dos recursos e sistematização de avaliações, fatores que influenciam o uso bem sucedido dos recursos de Tecnologia Assistiva, estudos sobre as 
causas de abandono dos recursos de Tecnologia Assistiva e estudos de eficácia (Scherer et. al., 2005; Copley \& Ziviani, 2004; Lovarini, McCluskey \& Curtin, 2006).

\section{Tecnologia Assistiva}

O paradigma de inclusão baseia-se na crença em uma sociedade para todos os seus cidadãos -é uma proposta de construção de cidadania. Nesse sentido, inclusão é entendida como um conjunto de ações a serem construídas cotidianamente, objetivando tanto a sensibilização da pessoa com necessidades especiais e de suas famílias sobre seus direitos, deveres e possibilidades como cidadãos, quanto da sociedade que passa a se responsabilizar por todos os seus membros, acolhendo-os de maneira indiscriminada e oferecendo-lhes possibilidades efetivas para a real participação e atuação destes em sociedade (Sassaki, 1999; Marins \& Palhares, 2007; Rocha, 2007; Rocha, Luiz \& Zulian, 2003; Sousa, Jurdi \& Silva, 2015).

Com isso, o conhecimento científico e tecnológico da atualidade vem impulsionando o desenvolvimento de novos instrumentos, com o objetivo de ampliar e/ou restaurar a função humana, aprofundando discussões em torno do planejamento de ambientes menos restritivos que propiciem a participação de todos. Nesta perspectiva é que, tanto o ambiente quanto os recursos, devem minimizar as limitações do indivíduo e potencializar suas habilidades; sendo que o ramo da ciência que pesquisa, desenvolve e aplica instrumentos, recursos, aparelhos ou procedimentos, que ampliam ou restauram a funcionalidade denomina-se Tecnologia Assistiva (TA). Tendo isso em vista, Buch et. al. (2014, p. 131) afirmam:

Em busca da sedimentação do conceito de cidadania fazem-se necessárias novas conquistas sociais que priorizem a melhoria da qualidade de vida de um maior número de pessoas. Estas conquistas, quando se tratam de pessoas com deficiência, dizem respeito não apenas a garantia de acesso, como eliminação de barreiras físicas, mas a um conjunto de ações que favoreçam a utilização dos serviços existentes na sociedade, através de procedimentos e recursos capazes de maximizar a funcionalidade, a segurança e o bem estar.

TA é um termo ainda novo, utilizado para identificar todo o arsenal de recursos e serviços que contribuem para proporcionar ou ampliar habilidades funcionais de pessoas com deficiência e consequentemente promover vida independente e inclusão. Recursos são todo e qualquer item, equipamento ou parte dele, produto ou sistema fabricado em série ou sob medida utilizado para aumentar, manter ou melhorar as capacidades funcionais das pessoas com deficiência. Serviços são definidos como aqueles que auxiliam diretamente uma pessoa com deficiência a selecionar, comprar ou usar os recursos acima definidos, segundo a ADA - American with Disabilities ACT (Bersch, 2014).

Ainda com base em Bersch (2014), entende-se que diariamente fazemos o uso de diversas ferramentas que tem como principal função nos auxiliarem nas atividades rotineiras tornando-as mais fáceis e simples, como por exemplo o uso de computadores, talheres, 
relógios, celulares, entre outros. A Tecnologia Assistiva, tem a mesma função dessas ferramentas, porém seu uso é destinado às funções desejadas e que, por algum motivo, estão impedidas de serem realizadas. A TA tem como principal objetivo auxiliar pessoas com qualquer tipo de deficiência a suprirem suas necessidades, serem mais independentes e que cada vez mais eles possam ser inseridos socialmente ampliando suas mobilidades, seus aprendizados e suas comunicações. Por fim, a classificação dos recursos de Tecnologia Assistiva se dá através dos objetivos funcionais que os mesmos se destinam.

\section{Produtos com Tecnologia Assistiva para mobilidade de usuários com Paralisia Cerebral}

Segundo Dutra \& Gouvinhas (2010), atualmente os produtos disponibilizados no mercado nacional por empresas especializadas na fabricação/comercialização de equipamentos de Tecnologia Assistiva direcionados a esse público apresentam pouca variedade em relação a uso de acessórios, design e dimensões. Tais fatores podem limitar o atendimento das exigências motoras desses usuários de maneira satisfatória.

Logo, a escolha de um dispositivo de assistência, ou seja, um equipamento que promova o aumento e/ou participação do indivíduo com incapacidade na execução de uma atividade, pode ser uma tarefa complexa. Todas as limitações e necessidades do usuário, do cuidador e do ambiente devem ser consideradas, pois seu somatório definirá como o dispositivo funcionará e como sua função será percebida (Pain \& McLellan, 2003). Sendo assim, entende-se que quanto maior o grau de limitação de movimento e comunicação de uma criança com Paralisia Cerebral, maior deve ser a atenção no momento de escolher o tipo de Tecnologia Assistiva a ser utilizada.

Segundo Oliveira, Lourenço \& Garotti (2008), a avaliação cognitiva das crianças com PC que apresentam grave envolvimento motor e possuem impedimentos na fala e na escrita manual, são dificultadas pela restrição de comunicação e pelo fato da maioria dos instrumentos utilizados requererem respostas verbais e/ou motoras. Por esperar respostas verbais ou escritas o educador encontra dificuldades na interação e na avaliação da aprendizagem desse aluno. Nesse sentido, os comportamentos acadêmicos básicos de leitura e escrita, na maioria das vezes, não são adquiridos satisfatoriamente, o que dificulta a inclusão na rede regular de ensino.

Oliveira, Lourenço \& Garotti (2008) complementam afirmando que dois fatores vão influenciar a qualidade e a velocidade do desenvolvimento cognitivo de uma criança: a capacidade de interação com o meio e a natureza desse meio. Portanto, a partir do princípio da tríade indivíduo - ambiente - desenvolvimento cognitivo, fica evidente que as crianças com PC apresentam desvantagens. A disfunção neuromotora pode interferir na auto-exploração e exploração do ambiente, entretanto isso não significa que a capacidade cognitiva esteja severamente comprometida. A redução da capacidade exploratória limita as experiências sensoriais e perceptivas, atrasando a aquisição dessas informações, o que poderá ser minimizado através de programas de ensino adequado às condições desses indivíduos. 


\section{Educação inclusiva}

O movimento de inclusão escolar foi marcante nos anos 90, a partir de discussões que buscavam superar os limites impostos pelo processo de integração (então vigente) e alcançar uma atenção integral às pessoas com deficiência. O ano de 1994 documentou esse movimento, quando foi realizada a Conferência Mundial sobre Necessidades Especiais: acesso e qualidade, na cidade de Salamanca (Espanha), considerada como um momento historicamente significativo (Plotegher \& El-Khatib, 2010). Plotegher \& El-Khatib (2010) ainda afirmam que a Declaração de Salamanca foi importante na questão da defesa da educação para todos e uniu 92 países e 25 organizações em prol desse direito, fazendo com que todos reconhecessem a necessidade e a urgência de garantir a educação de pessoas com deficiência nas redes regulares de ensino (UNESCO, 1994).

Ainda sobre o tema, Sassaki (1999) acrescenta que, enquanto conceito, a inclusão social é caracterizada como um processo pelo qual a sociedade se adapta para poder incluir pessoas com necessidades especiais, ao mesmo tempo em que estas se preparam para assumir seus papéis na sociedade. Nesse sentido, a inclusão se constitui como um processo bilateral no qual as pessoas, ainda excluídas, e a sociedade buscam, em parceria, equacionar problemas, decidir sobre soluções e efetivar a equiparação de oportunidades para todos.

Tendo isso em vista, e observando a crescente tecnologia presente nos dias atuais, é possível perceber que, cada vez mais, existem maneiras diferentes e mais eficazes de permitir maior mobilidade, autonomia, comunicação e, consequentemente, integração desses deficientes com todos os indivíduos presentes em seu ambiente escolar. Todavia, ainda existe uma grande dificuldade em inserir essas soluções nas redes de ensino no Brasil. Como afirma Pereira et. al. (2011), a falta de acessibilidade a determinados locais e serviços leva as pessoas com deficiência a se sentirem à margem da sociedade, o que gera, muitas vezes, perturbações de estima e comportamento, o que contribui ainda mais para a segregação social. Isso faz com que muitas crianças com PC sejam isoladas na sociedade, sem estímulos e oportunidades, o que dificulta seu desenvolvimento biopsicossocial, e acaba por desvalorizar as suas potencialidades. A sociedade é que está excluída da oportunidade da convivência, do compartilhamento e do crescimento coletivo, se referindo à criança com Paralisia Cerebral e sua família, que, geralmente, vivem à margem do sistema sócio-econômico cultural do Brasil.

Na tentativa de suprir essas dificuldades, a Declaração de Salamanca (UNESCO, 1994) colocou que o princípio das escolas inclusivas é a de que todos os alunos aprendam juntos, independente das dificuldades e diferenças que apresentem. A escola precisa adaptar-se para que o aprendizado seja garantido. Para isso o esforço tem que ser advindo não só dos alunos, pais e voluntários, mas também dos professores, funcionários e do sistema de ensino municipal, estadual e federal, que deve prover as condições para que os alunos com deficiência encontrem possibilidades concretas de aprendizagem e de interações com os colegas e professores. A declaração ainda pontua a importância do apoio suplementar aos alunos, necessário para assegurar uma educação mais eficaz. Assim, deve-se levar em consideração que a fase escolar é de extrema importância, e é nela que a criança desenvolve as principais habilidades desse âmbito, as quais estimulam a capacidade de realizar diversas 
outras atividades humanas. Logo, entende-se que são necessárias ações voltadas a inclusão desses educandos na escola.

\section{Método}

O público beneficiado com a TA desenvolvida neste trabalho são crianças cadeirantes com PC matriculados no ensino fundamental da rede municipal de educação regular de Florianópolis/SC, Brasil. Essa delimitação contempla jovens de 6 à 12 anos. Com o intuito de orientar as etapas envolvidas no desenvolvimento do produto em questão, optou-se por métodos e ferramentas tradicionalmente utilizadas na área do design. Contudo, em função das particularidades envolvidas no design de produtos e serviços com TA, foram realizadas adaptações metodológicas. Desse modo, o projeto foi pautado em três fases principais: 1) Análise do Problema; 2) Desenvolvimento de TA e; 3) Avaliação da TA Desenvolvida. É importante enfatizar que estas etapas são partes de um projeto mais amplo. O presente artigo se concentra na demonstração dos resultados obtido na Etapa 2. Porém, convém esclarecer o método como um todo para que se tenha uma compreensão global do trabalho desenvolvido de modo colaborativo.

Na fase de Análise do Problema foram realizadas atividades paralelas de pesquisa relacionadas ao estado da técnica nas questões relativas à mobilidade, comportamento motor (principalmente adequação postural, equilíbrio, habilidades motoras, dentre outros) e atividades diversas dos educandos com PC. Para o entendimento e coleta das necessidades dos clientes foram feitas visitas a escolas da Região Metropolitana de Florianópolis, a fim de realizar entrevistas com educandos e educadores e fazer uso da observação direta como meios de compreender a realidade da pesquisa. Ainda na primeira fase do projeto, para auxiliar na geração de especificações-meta do produto a ser desenvolvido, foram utilizadas ferramentas de projeto de produto como brainstormings, check- lists, a Matriz da Casa da Qualidade advinda do QFD (Quality Function Deployment) e ainda outras ferramentas metodológicas em design que se fizeram necessárias.

Na fase de Desenvolvimento de Tecnologia Assistiva foram elaborados desenhos à mão livre e com auxílio computacional que representaram possíveis soluções aos requisitos de projeto levantados na fase anterior. Uma vez selecionada a alternativa que melhor atendeu aos requisitos de projeto, com as respectivas especificações prévias de componentes, materiais e processos de fabricação possíveis, o conceito foi detalhado. Para tanto, foram gerados desenhos técnicos finais de conjunto e montagem e de cada componente projetado, a fim especificar sua produção. Softwares de modelamento virtual tridimensional serviram de auxílio nessa fase do desenvolvimento.

Na fase de Avaliação da Tecnologia Assistiva Desenvolvida, após a entrega dos resultados do projeto ao público-alvo, foi possível avaliar a satisfação dos clientes e a eficiência e eficácia do produto desenvolvido. Esta avaliação também possuiu um caráter interdisciplinar, abrangendo tanto aspectos humanos e da saúde, como a ergonomia e a biomecânica, quanto aspectos técnicos do produto, como desempenho elétrico e mecânico. Por fim, concluiu-se o projeto com a elaboração da documentação final solicitada pelos agentes financiadores do projeto. 
Convém salientar que, para este projeto, o termo 'produto' se refere a uma designação mais ampla do que o item físico manufaturado. Ele se refere ao sistema produto-serviço que o educando com Paralisia Cerebral (PC) pode usufruir, ou seja, os meios que são projetados com o fim de atender de maneira satisfatória os desejos e necessidades desse público-alvo. Já o termo 'cliente', utilizado neste projeto, se refere a qualquer pessoa que venha a interagir com o produto durante o seu uso, como a família, professores, fisioterapeutas, terapeutas ocupacionais, demais profissionais e o próprio usuário final do sistema, no caso o educando com PC.

\section{Resultados}

O principal objetivo deste tópico é apresentar os resultados referentes ao desenvolvimento de um projeto colaborativo que gerou um equipamento com TA, mais especificamente um sistema para mobilidade e adequação postural para ser utilizado por educandos com PC no ambiente escolar. O método apresentado no tópico anterior, portanto, deve ser entendido como um procedimento mais abrangente, cujas etapas descritas referem-se a um projeto que já vem sendo desenvolvido há alguns anos. Por isso, etapas anteriores às descritas neste trabalho já foram publicadas em outros artigos científicos em periódicos e eventos na área da pesquisa (Bergamin et. al., 2015; Buch et. al., 2014).

Como parte da obtenção dos resultados, o grupo de pesquisa envolvido neste desenvolvimento concentrou-se na obtenção das dimensões e proporções adequadas ao equipamento com TA. Além da consulta à bibliografia da área de ergonomia, foram obtidas informações junto aos profissionais que trabalham diretamente com as crianças que fazem parte do público a ser contemplado com esta proposta. A partir destes dados, foi possível modelar tridimensionalmente as diferentes posturas necessárias para o correto posicionamento do usuário no sistema de assento. A Figura 1 apresenta um dos métodos utilizados para buscar este objetivo.

Conforme apresentado na Figura 1, foi desenvolvido um manequim em papelão, com as dimensões básicas e principais articulações do corpo humano, cujas proporções correspondiam às das crianças com a faixa etária proposta para o projeto, em escala natural. Isso possibilitou a obtenção do esquema de quais seriam as superfícies de contato do produto com o usuário, método informalmente denominado de superfícies funcionais.

Consequentemente, a partir da obtenção das superfícies funcionais, foi possível criar o entorno desta interface com o usuário em forma de estrutura do produto, que envolve o desenho de conjunto do mesmo, com todos os seus mecanismos de funcionamento. Para tanto, foram realizados estudos para a definição da arquitetura do produto.

Esses estudos foram realizados com o intuito de demonstrar graficamente a possibilidade de ajustar o sistema de assento em três principais posicionamentos requeridos para o usuário, ou seja: sentado, reclinado e ereto (ou postura em pé). Por isso, pode-se observar na a implementação de princípios de solução em forma de mecanismos que realizassem estas funções de alteração de posicionamento dos componentes, como manoplas de ajuste, eixos para angulação, pinos para travamento das partes e molas a gás para auxiliar no deslocamento vertical da carga. Esta decisão de projeto nesta etapa possibilitou o desen- 
volvimento de um conceito que dispensa dispositivos eletromecânicos complexos e de alto custo para o funcionamento do produto.

Após a definição da arquitetura do produto, foi possível definir a lista final de materiais, os desenhos técnicos do produto, o memorial descritivo e todas as demais informações necessárias para a compilação do detalhamento técnico do produto com TA. A Figura 2 apresenta um rendering digital e descritivo do produto desenvolvido.

Conforme apresentado na Figura 2, o resultado deste projeto colaborativo é um equipamento que visa auxiliar a mobilidade e a adequação postural de educandos com PC no ambiente escolar. O produto é constituído de uma estrutura feita de chapas de aço carbono e de tubos de aço carbono de secção retangular e de secção circular, bem como de chapas de compensado naval. Esses principais itens de matéria-prima são de baixo custo e estão amplamente disponíveis no mercado brasileiro.

Outro diferencial do produto desenvolvido é a instalação de pistões a gás em combinação com outros mecanismos no sistema, que visam auxiliar o cuidador em diminuir seu esforço para modificar a postura da criança, seja para a posição sentada, reclinada ou ereta, a depender da atividade a ser exercida pelo educando com PC. A Figura 3, por exemplo, apresenta uma representação do posicionamento da criança em posição sentada (para a realização de atividades como as de estudo e alimentação) e outra representação do equipamento na posição reclinada (para a realização de atividades como as de descanso). É importante enfatizar que esta estrutura apresentada na Figura 3 se trata de um produto padrão, que pode ser fabricado em grande escala, mas que necessita de adaptações para atender a uma criança específica com PC. De fato, o propósito do projeto era o desenvolvimento de uma estrutura básica que pudesse receber um sistema de assento que fosse customizado para seu usuário, aplicando-se os conceitos de projeto modular.

Ainda, para fins de demonstração quanto às possibilidades de funcionamento do produto com TA, a Figura 4 apresenta o exemplo de um sistema de assento ajustado para a posição ereta (para a realização de atividades como as de recreação, educação física e demais interações que mantenham a criança no mesmo nível dos demais colegas no ambiente escolar).

Observa-se, portanto, nas Figuras 2 a 4, o detalhamento do produto com TA desenvolvido de modo colaborativo, bem como os diferentes ajustes possibilitados pelo equipamento para atender às diferentes posturas necessárias para a inclusão de educandos com PC na realização das diversas atividades no ambiente escolar.

É importante destacar que este artigo se propôs a apresentar o desenvolvimento do produto com TA até a etapa de modelamento virtual e detalhamento técnico do mesmo, onde pode-se observar um conceito inovador que pretende resolver problemas de mobilidade, adequação postural e de interface entre educador, produto e educando. Posteriormente, pretende-se publicar novos artigos científicos com os resultados das etapas de prototipagem física do produto, adequação do sistema de assento para uma criança específica e realização de testes para avaliar o equipamento. O presente projeto de pesquisa encontra-se na fase de customização do sistema de assento para o protótipo, que está sendo construído. 


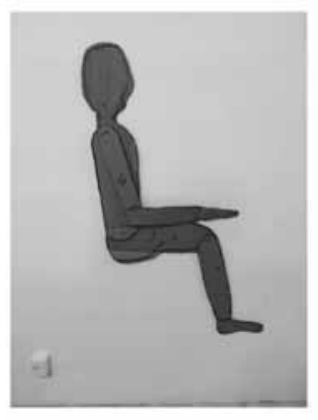

Figura 1.

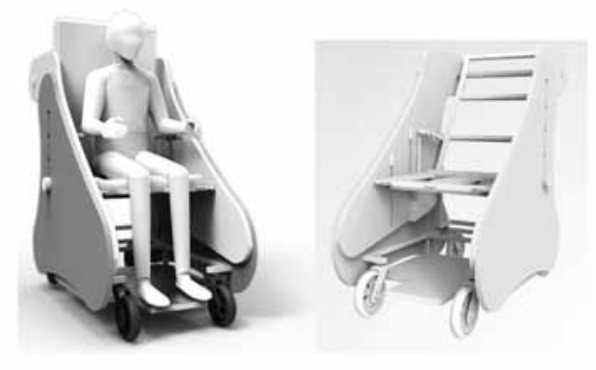

Figura 3.

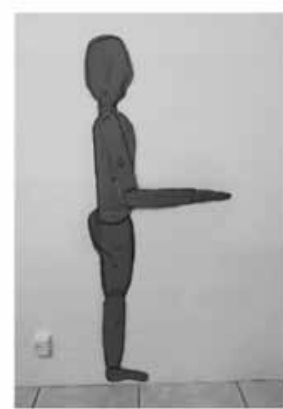

Figura 2.

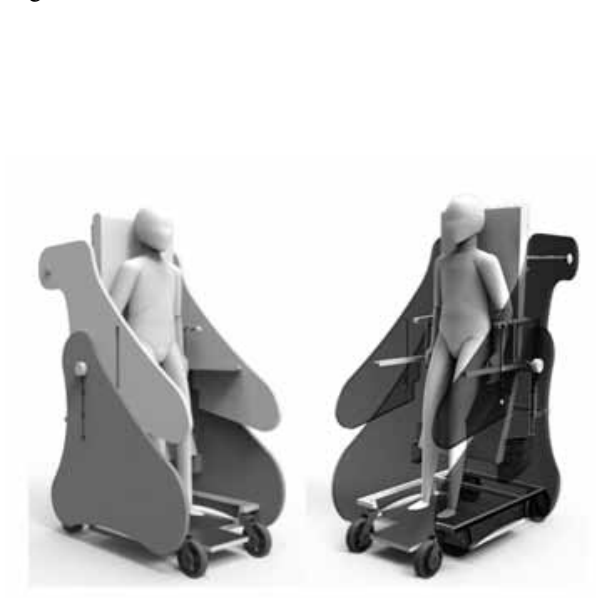

Figura 4.

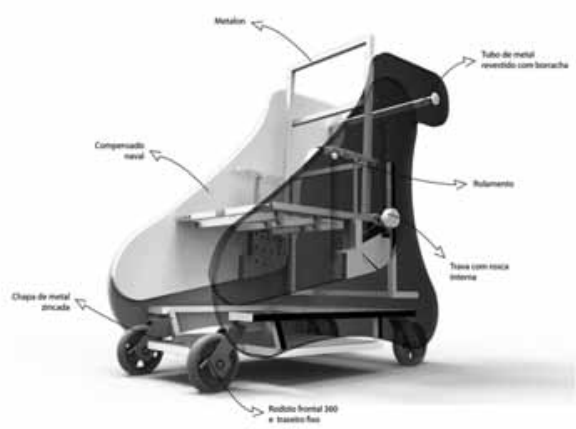




\section{Discussão dos resultados}

O resultado do projeto foi um equipamento inovador, com a possibilidade de adaptar sistemas de assentos diversos, cujo conceito visa se desvencilhar do estereótipo da cadeira de rodas tradicional e ampliar a gama de opções para uma melhor mobilidade e adequação postural do usuário. O novo produto, em um único sistema que utiliza pistões à gás e dispensa mecanismos eletromecânicos dispendiosos, possibilita a acomodação da criança em três diferentes posturas de modo prático para o cuidador: 1) Sentado, para realização de atividades como as de estudo e alimentação; 2) Reclinado, para a realização de atividades como as de descanso; 3 ) Ereto, para a realização de atividades como as de recreação, educação física e demais interações que mantenham a criança no mesmo nível dos demais colegas no ambiente escolar. Espera-se que a divulgação desta iniciativa continue a fortalecer outras ações de design que visam promover às pessoas com deficiência uma condição cada vez mais adequada para sua autonomia, interação e consequente inclusão nas atividades relativas ao seu próprio desenvolvimento humano.

Ainda, observou-se neste estudo que, apesar da ampla bibliografia acerca da Paralisia Cerebral, há poucos artigos e trabalhos acadêmicos que abordem o tema direcionado para mobilidade de crianças e adolescentes no ambiente escolar. Os artigos encontrados tratavam de temas relacionados ao entorno da criança com Paralisia Cerebral, como mobiliário e estrutura local para receber os alunos. É de extrema importância que os alunos com PC consigam desempenhar as mesmas funções que os alunos sem PC, assim os permitindo um bom desenvolvimento escolar. Além de recursos pedagógicos adaptados, adaptações no ambiente físico e adequações no mobiliário da escola, é de extrema importância visar a mobilidade e a interação em classe com a cadeira de rodas adaptada.

Cada criança e adolescente portadora de PC têm necessidades distintas, assim como sua adequação postural, pois cada indivíduo é único em sua condição física. As adaptações visam facilitar e possibilitar as atividades escolares assim como sua melhor integração nesse ambiente, trabalhando tanto em sua condição motora quanto a interação social e as experiências proporcionadas nesse ambiente. Portanto, para o desenvolvimento de novos recursos com TA para portadores de PC, pode-se propor que na implementação do projeto seja analisado todo o âmbito que circunda a pessoa com deficiência. Sugere-se ainda que sempre se analise a adequação postural individual de cada usuário, que é de supra importância para seu correto posicionamento, além de facilitar sua interação com o ambiente e as pessoas ao redor, conforme foi ilustrado pelo caso do produto desenvolvido e apresentado neste artigo.

\section{Conclusões}

Este artigo apresentou de forma concisa os resultados do projeto de um equipamento com Tecnologia Assistiva, exclusivamente desenvolvido para atender educandos com Paralisia Cerebral em um rede de ensino no Brasil. Devido ao contexto socioeconômico no qual a iniciativa está inserida, o produto tinha como requisito ser de baixo custo e atender seu público em questões relativas à mobilidade, comportamento motor e à realização de ati- 
vidades diversas no ambiente escolar. O projeto teve um caráter colaborativo, pois contou com a participação de profissionais das mais diversas áreas que circundam o tema da TA, como Design, Engenharia, Pedagogia, Terapia Ocupacional e Fisioterapia. As etapas do projeto foram orientadas através de métodos e ferramentas tradicionalmente utilizadas na área do Design. Embora ainda não tenha sido totalmente concluída e entregue ao seu público, a execução e implementação da proposta visam proporcionar aos educandos uma situação adequada para sua autonomia e interação, o que gera inclusão e qualidade de vida. Também foi contribuição deste estudo realizar o levantamento de dados com uma abordagem referenciada para prover maior ênfase na mobilidade de educandos com Paralisia Cerebral, pois, após a pesquisa inicial, foi notada a escassez de produções textuais científicas concisas que abordassem o tema. Esse assunto foi investigado por conta da crescente importância que se dá ao tema da Tecnologia Assistiva, a qual proporciona melhores condições para o usuário com deficiência. Enfatiza-se que todos os envolvidos direta e indiretamente nesse tema, devem ter um conhecimento maior sobre os benefícios da mobilidade e adequação postural para as pessoas com Paralisia Cerebral, especialmente na rede de ensino, pelo fato deste público estar vivendo uma fase fundamental de seu desenvolvimento humano. Adaptar o ambiente ao redor do aluno com PC é importante, mas foi visto que a mobilidade é a principal questão da interação. A importância de produções textuais quem enfatizem a mobilidade de pessoas com PC é essencial para auxiliar o fomento ao desenvolvimento de novos produtos que visem proporcionar as melhores experiências aos seus usuários.

\section{Bibliografia}

Alves, A. C. \& Matsukura, T. S. (2011). "Percepção de alunos com paralisia cerebral sobre o uso de recursos de tecnologia assistiva na escola regular" em Revista Brasileira de Educação Especial, vol. 17, n. 2, p. 287-304, maio-agosto de 2011, Marília.

Bergamin, G. S. et. al. (2015). Aplicação do QFD no design de tecnologia assistiva para inovação no contexto educacional. In: IV International Conference on Design, Engineering and Management for innovation - IDEMi 2015. p. 1-13. Florianópolis.

Bersch, R. (2014). Introdução à tecnologia assistiva. Disponível em: <http://www.assistiva. com.br/tassistiva.html\#artigos>. Acesso em: 10 de junho de 2016.

Bersch, R.C.R. \& Pelosi, M. B. (2007). Portal de ajudas técnicas para a educação: equipamento e material pedagógico para a educação, capacitação e recreação da pessoa com deficiência física. Tecnologia Assistiva: recursos de acessibilidade ao computador. Brasília: Secretaria de Educação Especial.

Buch, V. D.et. al. (2014). "Análise da demanda para o desenvolvimento da tecnologia assistiva direcionada a educandos com paralisia cerebral" em Revista Human Factors in Design, vol. 3, n. 5, p. 03-14, julho de 2014, Florianópolis.

Copley, J. \& Ziviani, J. (2004). "Barriers to the use of assistive technology for children with multiple disabilities" em Occupational Therapy International, vol. 11, n.4, p. 229-43, 2004. 
Dutra, F. C. M. \& Gouvinhas, R. P. (2010). “Desenvolvimento de protótipo de cadeira de banho para indivíduos com paralisia cerebral tetraparética espástica" em Revista Produção, vol. 20, n. 3, julho/Setembro de 2010, São Paulo.

Geralis, E. (2007). Crianças com paralisia cerebral: guia para pais e educadores. Porto Alegre: Artmed.

Lovarini, M.; Mccluskey, A. \& Curtin, M. (2006). Editorial: “Critically Appraised Papers Limited high-quality research on the effectiveness of assistive technology" em Australian Occupational Therapy Journal, vol. 50, p. 53, 2006.

Marins, S. C. F. \& Palhares, M. S. (2007). “Educação inclusiva: relato de uma experiência a partir da visão dos gestores municipais" em Cadernos de Terapia Ocupacional da UFSCar, vol. 15, n. 1, p. 69-89, 2007, São Carlos.

Oliveira, F. T. (2007). Estudo do mobiliário escolar durante o desempenho de atividades lúdicas por alunos com paralisia cerebral espástica. 100f. Dissertação (Mestrado) - Faculdade de Filosofia e Ciências, Universidade Estadual Paulista, Marília.

Oliveira, A. I. A.; Lourenço, J. M. Q. \& Garotti, M. F. (2008). Tecnologia Assistiva: pesquisa e prática. Belém: EDUEPA.

Pain, H. \& McLellan, D. L. (2003). "The relative importance of factors affecting the choice of bathing devices" em British Journal Of Occupational Therapy, vol. 66, n. 9, p. 396-401, 2003.

Pereira, L.M.F. et. al. (2011). "Acessibilidade e crianças com paralisia cerebral: a visão do cuidador primário" em Revista Fisioterapia em Movimento, vol. 24, n. 2, p. 299-306, abril/ junho de 2011, Curitiba.

Plotegher, C. B. \& El-Khatib, U. (2010). “Inclusão Escolar: ilusão ou realidade?” em Revista Âmbito Jurídico, Revista jurídica eletrônica, vol. 13, n. 82, novembro de 2010, Rio Grande.

Rocha, A. N. D. C. \& Deliberato, D. (2012a). "Atuação do terapeuta ocupacional no contexto escolar: o uso da tecnologia assistiva para o aluno com paralisia cerebral na educação infantil” em Revista de Terapia Ocupacional da Universidade de São Paulo, vol. 23, n. 3, p. 263-273, setembro de 2012, São Paulo.

Rocha, A. N. D. C. \& Deliberato, D. (2012b). “Tecnologia assistiva para a criança com paralisia cerebral na escola: identificação das necessidades” em Revista Brasileira de Educação Especial, vol. 18, n. 1, p. 71-92, março de 2012, Marília.

Rocha, E. F. A. (2007). "Terapia Ocupacional e as ações na educação: aprofundando interfaces” em Revista de Terapia Ocupacional da Universidade de São Paulo, vol. 18, n. 3, p. 122-127, 2007, São Paulo.

Rocha, E. F.; Luiz, A. \& Zulian, M. A. R. (2003). “Reflexões sobre as possíveis contribuições da terapia ocupacional nos processos de inclusão escolar" em Revista de Terapia Ocupacional da Universidade de São Paulo, vol. 14, n. 2, p. 72-78, 2003, São Paulo.

Sassaki, R. K. (1999). Inclusão: construindo uma sociedade para todos. $3^{a}$ edição. Rio de Janeiro: WVA.

Scherer, M. J. et. al. (2005). "Predictors of assistive technology use: The importance of personal and psychosocial factors" em Disability and Rehabilitation, vol. 27, n. 21, p.1321-1331, 2005.

Sousa, P. G. F.; Jurdi, A. P. S. \& Silva, C. C. B. (2015). "O uso da tecnologia assistiva por terapeutas ocupacionais no contexto educacional brasileiro: uma revisão da literatura" em Caderno de Terapia Ocupacional da Ufscar, vol. 23, n. 3, p. 625-631, agosto de 2015, São Carlos. 
UNESCO (1994). Declaração de Salamanca e enquadramento da ação na área das necessidades educativas especiais. Brasília: CORDE.

Washington, K. et. al. (2002). "The effects of a contoured foam seat on postural alignment and upper-extremity function in infants with neuromotor impairments" em Physical Therapy, vol. 82, n. 11, p. 1064-1076, 2002.

Resumen: Este artículo presenta los resultados del desarrollo de un producto con Tecnología Asistida (TA) de bajo costo para auxiliar a los educandos con Parálisis Cerebral (PC) en una red municipal de enseñanza en Brasil, en cuestiones relativas a su movilidad, comportamiento motor ya la realización de actividades diversas, dentro y fuera del aula. El proyecto fue colaborativo y orientado con el uso de métodos y herramientas tradicionalmente utilizadas en el área del diseño. La ejecución e implementación de la propuesta tiene por objeto proporcionar a los educandos una situación adecuada para su autonomía, interacción y consecuente inclusión en las actividades relativas a su propio desarrollo humano.

Palabras clave: Tecnología Asistida - Parálisis Cerebral - Proyecto Colaborativo.

Abstract: This paper presents the results of the development of a low cost Assistive Technology (AT) product to assist students with Cerebral Palsy (CP) in a municipal education network in Brazil, in questions related to their mobility, motor behavior and achievement of various activities, both inside and outside the classroom. The project was collaborative and oriented with the use of traditionally used methods and tools in the area of design. The development and implementation of the proposal aim to provide students with an adequate situation for their autonomy, interaction and consequent inclusion in activities related to their own human development.

Keywords: Assistive Technology - Cerebral Palsy - Collaborative Project. 